\title{
Vibrational communication and evidence for vibrational behavioural manipulation of the tomato potato psyllid, Bactericera cockerelli
}

\author{
Sabina Avosani1 ${ }^{1,2, *}$, Thomas E.S. Sullivan ${ }^{3}$, Marco Ciolli1,4, Valerio Mazzoni², and \\ David Maxwell Suckling 3,5
}

1 DICAM Department of Civil, Environmental and Mechanical Engineering, University of Trento, Trento, Italy

2 Research and Innovation Centre, Fondazione Edmund Mach, San Michele all'Adige (TN), Italy

3 The New Zealand Institute for Plant and Food Research Ltd, Lincoln

${ }^{4}$ C3A, Center Agriculture Food Environment, University of Trento, San Michele all'Adige (TN), Italy

5 School of Biological Sciences, University of Auckland, New Zealand

* Corresponding author: sabina.avosani@unitn.it

With 3 figures and 8 tables

\begin{abstract}
Vibrational pest management techniques involve the manipulation of the mating behaviour of the target species. Development of such techniques require a deep understanding of the pair formation process. Two types of bioassays were conducted to determine whether a vibrational disruptive approach could be used for Bactericera cockerelli. First, we conducted trials with either single individuals or pairs of a male and a female to ascertain whether B. cockerelli uses vibrational signals to achieve mating. Second, playback trials were conducted using two different female signals to manipulate the behaviour of males. Signals emitted during the trials were recorded using a laser vibrometer from the surface of a leaf where either single individuals or pairs of $B$. cockerelli were released. We described the communication phases that led to mating and the associated male and female signals. Pair formation started with a male call followed by a female response, which established a vibrational duet. During the female reply, the male searched for the female without emitting vibrational signals. Mating could be achieved if the male could maintain the female replies and reach her. In the playback trials, two different female playbacks attracted males to the signal source. Furthermore, males stimulated with female playbacks spent more time near the source of the signal than insects in the silent control group. We concluded that the $B$. cockerelli mating behaviour relies on vibrational signals and is potentially susceptible to vibrational manipulation, thus a future vibrational management technique could be developed to monitor or control this species.
\end{abstract}

Keywords: vibrational pest control, behaviour, tomato potato psyllid, (Hemiptera: Triozidae), pair formation

\section{Introduction}

Innovative pest management strategies can involve manipulation of the target organism's sexual behaviour using specific external stimuli, in order to reduce the use of pesticides in agriculture (Polajnar et al. 2015). To control the population of an insect pest, its behaviour can be altered either to attract/repel it with a lure-and-kill/push-and-pull tactic or to disrupt mating (Foster \& Harris 1997). However, the prerequisite for setting an efficient control method is to identify and characterise the key signals used to achieve mating by the target species (Pedigo \& Rice 2014; Pertot et al. 2017). Therefore, it is necessary to assess which sensory modalities control relevant behaviours (Mazzoni et al. 2017). During communication, emitted and received signals convey information about identity, physiological condition and position of the sender, which can elicit specific responses in the receiver (Endler 1992).

Exchange of substrate-borne vibrations is a widespread communication modality among insects and is of crucial importance for mating (Čok1 \& Virant-Doberlet 2003; VirantDoberlet \& Cokl 2004; Cocroft \& Rodríguez 2005; VirantDoberlet \& Zezlina 2007). In this regard, many hemipteran species that use vibrations to communicate are agricultural pests (Kanmiya 2006; Mazzoni et al. 2009; Mazzoni et al. 2017; Derlink et al. 2018). It has been recently suggested that the behaviour of these insects can be manipulated by means of mechanical stimuli that interfere with the vibrational 
communication (Polajnar et al. 2016). For instance, specific disruptive vibrational signals transmitted through plants decreased the mating success of the grapevine leafhopper, Scaphoideus titanus, in both laboratory and open field trials (Eriksson et al., 2012, Polajnar et al., 2015). A similar approach was proposed for Homalodisca vitripennis (Gordon et al. 2017; Nieri et al. 2017; Krugner \& Gordon 2018) and Empoasca vitis (Nieri \& Mazzoni 2018), for which specific playbacks were designed to interfere with intraspecific communication and thus to disrupt the pair formation process. Besides mating disruption, another vibrational approach for pest control involve mechanical stimuli to attract insects into traps, as suggested for the brown marmorated stink bug, Halyomorpha halys. In this case, the existing pheromone trap is under implementation with a specific vibratory stimulus that brings males into the device (Mazzoni et al. 2017). Hence, the playback of species-specific vibrations in an integrated pest management approach could be expected to be applied for other pest insects whose communication relies on vibrational signals.

According to this, many species among Psylloidea are important agricultural pest (Munyaneza 2010) and use vibrational signals to achieve mating (Percy et al. 2006), as reported for the Asian citrus psyllid Diaphorina citri (Wenninger et al. 2009; Hall et al. 2013). In this and other psyllid species, the exchange of signals between the male and female allows the male to reach the replying partner on the leaf (Percy et al. 2006; Wenninger et al. 2009; Eben et al. 2015). With this knowledge, a trapping strategy has been developed and tested with $D$. citri, using a system that detected the male signals and transmitted an attractive vibrational stimulus as response (Mankin et al. 2013). For these reasons, it would be worthy to assess whether similar vibrational control techniques could be designed and applied against other psyllid pests.

The tomato potato psyllid, Bactericera cockerelli (Šulc) (Hemiptera: Triozidae) became one of the major economic pests in New Zealand after its introduction from North America (Liu \& Trumble 2007; Teulon et al. 2009). Bactericera cockerelli can transmit a bacterium, Candidatus Liberibacter solanacearum, which is the causal agent of 'zebra chip' disease in potato plants (Hansen et al. 2008; Liefting et al. 2009). Characterisation of the signals involved in the sexual communication of this pest could lead to the development of control practices based on behavioural manipulation, providing an alternative to insecticides, which represent the current management approach (Goolsby et al. 2007; Berry et al. 2009). Chemical signals are involved in the sexual communication of some species within the Cacopsylla genus (Soroker et al. 2004; Horton \& Landolt 2007) and there is evidence that $B$. cockerelli males move towards volatile chemical compounds emitted by conspecifics (Guédot et al. 2010). However, the role of vibrational signals in the mating behaviour and the attractiveness of these stimuli remain unclear. Some psyllids use vibrational signals to identify and eventually localise a potential mate, and in some taxa, pair formation relies on a tightly synchronised duet (Tishechkin 2005; Percy et al. 2006; Wenninger et al. 2009). It has been recently reported that $B$. cockerelli males emit substrate-borne signals and that the playback of synthetic male signals could elicit behavioural responses from other conspecifics (Sullivan et al., submitted for publication). Nevertheless, neither the pair formation process nor the male and female signals have been described yet. Hence, we carried out behavioural assays aimed to provide a detailed characterisation of the inter-sexual communication and the associated vibrational signals. Moreover, we conducted playback trials using pre-recorded signals of $B$. cockerelli female to evaluate whether the male behaviour is vulnerable to manipulation.

\section{Materials and methods}

\subsection{Insect rearing}

A colony of $B$. cockerelli was established under controlled conditions $\left(23 \pm 2{ }^{\circ} \mathrm{C}, 60 \% \pm 5 \% \mathrm{RH}, 16: 8 \mathrm{~L}: \mathrm{D}\right)$ in a climate chamber at Plant and Food Research in Lincoln (Canterbury, New Zealand). Insects were maintained on capsicum (Capsicum annuum) inside rearing cages (Bugdorm-6620, MegaView Science Co., Ltd., Taiwan; $60 \mathrm{~cm} \times 60 \mathrm{~cm} \times$ $120 \mathrm{~cm})$. Nymphs were collected from the colony and reared to the adult stage in a separate cage, which had the same size as the previous ones. Molted virgin adult males and females were used for experiments after melanisation (2-4 days).

\subsection{Recording vibrational signals}

Recordings were conducted at room temperature (25 \pm $\left.2{ }^{\circ} \mathrm{C}\right)$ on a vibrational dampening steel plate $(1.2 \mathrm{~m} \times 1.2 \mathrm{~m}$ $\times 10 \mathrm{~mm}$; Slade Engineering, Christchurch, New Zealand) that was placed on an array of nine insulating rubber pads (diameter $6.35 \mathrm{~cm}$; Sorbothane Hemisphere Rubber Bumper, IsolateIT, Burlington, USA) over a table. Vibrational signals and behaviours were recorded from a detached capsicum leaf with the stem placed in a plastic vial $(100 \mathrm{ml})$ filled with water. To detect the vibrational signals, a laser vibrometer (Polytec model PDV 100, Waldbrann, Germany) was set on the steel plate and pointed onto a piece $(0.5 \times 0.5 \mathrm{~cm})$ of reflective tape glued to the adaxial surface of a capsicum leaf (approximate surface $12 \times 8 \mathrm{~cm}$ ). To prevent insects from escaping, the leaf was contained in a plastic cage $\left(20 \mathrm{~cm}^{2}\right)$ with a circular opening on the top for the laser beam (diameter $6 \mathrm{~cm})$. The cage was set above a Plexiglas cube $\left(30 \mathrm{~cm}^{3}\right)$, which was placed on the steel plate. In this way, the laser and the leaf were at the optimal stand-off distance that ensures a better signal-to-noise ratio. Four insulating rubber pads were placed under the cube to reduce background vibrational noise. Recorded signals were digitized and stored via a sound card (M-Audio Fast Track Pro, M-Audio, United Kingdom) 
at a $48 \mathrm{kHz}$ sample rate and 24-bit resolution on a laptop computer (HP, EliteBook 8460 p) using Raven Pro 1.5 (The Cornell Lab of Ornithology, Ithaca, NY, USA). To associate the behaviour and respective emission of vibrational signals, insect movements were continuously monitored using two cameras (Logitech Quickcam Pro 9000 webcam, Logitech International S.A., Lausanne, Switzerland, and Microsoft ${ }^{\circledR}$ LifeCam HD-5000, Microsoft Corporation; U.S.A.) focused on the adaxial and abaxial sides of the leaf, respectively. The HandyAvi (Version 4.3C (C) Anderson's AZcendant Private Ltd, Singapore) time lapse software was used to capture psyllid signalling behaviour at 1 frame/s.

\subsubsection{Test 1: Vibrational signals associated with pair formation in B. cockerelli}

To characterise the vibrational signals associated with pair formation in $B$. cockerelli, behavioural trials were conducted during November and December 2018 between 08:00 and 17:00 $\mathrm{h}$ using either individuals or male-female pairs. In the individual trials, a male $(n=56)$ or a female $(n=37)$ was placed on the leaf and its vibrational signalling behaviour was recorded for 15 minutes. In the trial with pairs $(n=62)$, a male and a female were released in a random order on opposite sides of the leaf. The behaviour was recorded until a duet occurred or for 15 minutes in absence of vibrational signals. If a duet was established within the 15-min period, the trial was extended for another $30 \mathrm{~min}$ in order to provide a reasonable amount of time to the searching individual to find the partner on the leaf. To describe the psyllids' signalling activity, when applicable, we measured: (1) the calling latency, i.e., the time from the beginning of the trial to the emission of the first vibrational signal; (2) the number of signals emitted during the trial; (3) the latency to first duet, as the first reply to a signal regardless of gender; (4) the female response latency, as the delay of the female signal from the onset of the male signal; (5) the searching time, i.e., the time between the onset of the male search and the copulation; (6) and the replying rate of female, as the rate between the total number of female replies and male calls during the trial. We also measured (7) the mating success as the number of copulation events after the establishment of the male-female duet. To identify possible differences both between and within each phrase (see definitions below) of the Male Calling Signal (MCS, see results below), we compared the temporal and spectral parameters of the pulses at the beginning and at the end of each phrase with the Friedman test (nonparametric repeated measures ANOVA) with replications followed by pairwise multiple comparisons (Siegel \& Castellan Jr 1988). We selected six non-consecutive pulses for each phrase within a signal. In particular, three pulses were sampled at the beginning and three pulses were sampled at the end of each phrase (within the first and the last 5-6 pulses of the phrase, respectively), always including the first and last pulse. A Wilcoxon signed rank test was performed in order to detect possible differences in the spectral or temporal parameters between the MCS and the Female Response Signal (FRS, see results below). Specifically, the first 50 and the last 50 pulses were sampled from both the MCS and the FRS of the male $(n=22)$ and the female $(n=22)$, respectively, and then compared. The criterion of 50 pulses provided an appropriate description of the first and last sections of the MCS and FCS, since these are very long signals composed of brief pulses with a high repetition time (see results below). The durations of MCS and FRS were compared using a non-parametric Wilcoxon test with a continuity correction (Steel 1959). Statistical analyses were conducted using KyPlot version 2.0 beta 15 (1997-2001 Koichi Yoshioka) and Past 3 (Hammer and Harper Øyvind Hammer, Natural History Museum, and University of Oslo). Vibrational signals were identified and named according to their structure and behavioural context (see definition below). The spectral analysis was performed with Raven Pro 1.5 (The Cornell Lab of Ornithology, Ithaca, NY, USA) after a Fast Fourier Transform (FFT) type Hann, window length of 256 samples and $89.9 \%$ of overlap. The following parameters were measured when applicable for each signal, phrase, and pulse: duration, pulse repetition time (PRT, time from the onset of two consecutive pulses) and dominant frequency (Df). Results are presented as means with standard deviation (SD), range (min. and max.), together with the number of signals analysed for each individual $(\mathrm{N})$ and number of insects (n) from which signals were obtained.

\subsubsection{Test 2: Signal playback tests}

The aim of this test was to assess the effect of vibrational stimuli on males. The tested stimuli consisted of two playbacks of natural female signals that were previously recorded from a capsicum leaf. Two female playbacks were made using the audio software Adobe Audition 3.0 (Adobe Systems, Inc., San Jose, CA, USA). Specifically, female playback 1 (FPB1) consisted of two female signals. The first signal was obtained from a Female Attraction Signal (FAS, see results below) (duration: $23.72 \mathrm{~s}$ ) and was composed of 37 pulse trains of increasing duration (range 0.08 to $3.56 \mathrm{~s}$ ). The second signal was obtained from a Female Response Signal (FRS, see results below); it was shorter (21.53 s) than the FAS and consisted of five long pulse trains (range 1.51 to $8.02 \mathrm{~s}$ ). Between the two signals, there was a period of silence of $25.05 \mathrm{~s}$. The female playback 2 (FPB2) was similar to FPB1, except for a longer second signal (38.55 s, with the last pulse train of $24.97 \mathrm{~s}$ instead of $8.02 \mathrm{~s}$ ), whose duration was more similar to the mean duration of the natural FRS (see results below) compared to the duration of the second signal of the female playback 1 . For both playbacks, after the second signal, there were 25 seconds of silence. The PRT and the frequency ranges within the signals were not modified, while the relative amplitude of the playbacks measured from the plant was adjusted to not exceed the insect natural amplitude. 
Playbacks were transmitted into the substrate using an electromagnetic mini shaker (Direct Drive Linear Motor, model DDLM-038-051-01, MotiCont, Los Angeles, California, USA) in direct contact with the adaxial side of the capsicum leaf (approximate dimensions of the leaf, considering both lamina and petiole: $18 \times 10 \mathrm{~cm}$ ). A sharpened steel rod was screwed at the top of the device, which was physically separated from the anti-vibration table with a clamp standing on a nearby table. A laser vibrometer was pointed on the adaxial side of the leaf in order to ensure that the playback was being transmitted and to record the vibrational signals emitted by the insects during the trials.

\section{Test 2a: Female playback 1 (FPB1)}

A male $(\mathrm{n}=19)$ was placed on the leaf, at least $15 \mathrm{~cm}$ away from the tip of the mini shaker. After 1 minute of a silent acclimation period, the FPB1 was transmitted as a loop into the substrate for 10 minutes. The control group consisted of males $(n=19)$ left in silence for 12 minutes.

\section{Test 2b: Female playback 2 (FPB2)}

A male $(\mathrm{n}=19)$ was placed on the leaf, at least $15 \mathrm{~cm}$ away from the tip of the mini shaker. After 12 minutes of silence, the FBP2 was transmitted as a loop into the substrate for 10 minutes. In this way, the males left in silence for $12 \mathrm{~min}$ utes provided the control group of the trial with the FPB1. As a control for the FPB2 test, a trial $(n=19)$ with identical setup but in absence of playback (22 minutes of silence) was performed.

For both tests, if the playback did not elicit the emission of any vibrational signal by the insect, the recording was stopped. However, if the male responded to the stimulus, the trial was extended by 30 minutes to determine whether the male reached the mini shaker.

In the playback tests (the 'treatments'), we counted the number of (1) signalling males, (2) searching males, (3) males that reached the stimulation point (see definitions below), (4) males that touched or walked onto the mini shaker, and (5) the searching time. As a measure of the signal attractiveness to males, we counted (6) the number of males that remained close to the signal source (stimulation point) for a minimum of $1 \mathrm{~min}$ from the moment they reached it. We also counted the (7) number of males that responded to the playback. In Test $2 \mathrm{a}$ and $2 \mathrm{~b}, \mathrm{a} \mathrm{G}$ test in contingency tables $(2 \times 2)$, Williams-corrected was used to evaluate the effect of the playback on males by comparing treatments and silent controls for (1), (3), (4), and (6). Since we defined the 'searching males' as individuals that walked when stimulated with playback and the 'duetting males' as individuals that responded to the playback (see definitions below), we did not perform any statistics on (2), (5), and (7) between treatments and silent controls. The $\mathrm{G}$ test in contingency tables $(2 \times 2)$, Williams-corrected, was used to compare (2), (3), (4), (6), and (7) between the playback treatments of the
Test $2 \mathrm{a}$ and $2 \mathrm{~b}$. Since the acclimation time differed between the treatments of Test $2 \mathrm{a}$ and $2 \mathrm{~b}$, we did not compare (1). A Kruskal-Wallis test followed by Mann-Whitney pairwise, Bonferroni-adjusted, was used to compare (5) between treatments.

\subsection{Definitions}

Calling signal. Signal emitted spontaneously to trigger a reply from the opposite sex (Booij 1982; Tishechkin 2003).

Pulse. Physically unitary or homogeneous sound, composed of a brief succession of sine waves (Broughton, 1963, Alexander 1967).

Pulse train. Succession of repetitive and temporally welldistinct pulses (e.g. Mazzoni et al., 2009).

Phrase. Sequence of regularly repeated pulse trains with distinctive time and amplitude pattern.

PRT. Pulse repetition time, time from the onset of two consecutive pulses within a pulse train.

MCS. Male Calling Signal of B. cockerelli.

FRS. Female Response Signal of B. cockerelli.

FAS. Female Attraction Signal of B. cockerelli.

Signalling males. Individuals that emitted, spontaneously or after the playback, at least one vibrational signal during the trial.

Searching males. Individuals that responded to playback by emission of vibrational signals and also walked upon stimulation by playback.

Duetting males. Individuals that established a duet with the female playback.

Searching time. Period from the onset of the search until the arrival of the male to the stimulation point or until the end of trial.

Stimulation point. Area $(\varnothing 1 \mathrm{~cm})$ around the point of the leaf in direct contact with the mini shaker, considering both sides of the leaf.

\section{Results}

Emission of vibrational signals by $B$. cockerelli males and females was always accompanied by rapid wing movements in a vertical plane and dorso-ventral movements of the abdomen.

\subsection{Test 1: Vibrational signals associated with pair formation in $B$. cockerelli}

\subsubsection{Single males}

Among males tested alone, $50 \%(\mathrm{n}=56)$ emitted at least one signal after being released on the leaf, and 24 of these males were analysed. Signalling latency varied considerably amongst individuals, while the duration of the signal was relatively constant (Table 1). The number of signals emitted in the given time of the trial varied amongst males (Table 1) 
Table 1. Temporal and spectral parameters of the Male Calling Signal (MCS) of Bactericera cockerelli.

\begin{tabular}{|c|c|c|c|c|c|}
\hline & Mean \pm SD & Min & Max & $\mathbf{n}$ & $\mathbf{N}$ \\
\hline Signalling latency (s) & $292.9 \pm 224.4$ & 0 & 877.6 & 24 & 1 \\
\hline Duration of MCS (s) & $24.4 \pm 4.3$ & 17.5 & 33.4 & 24 & 2 \\
\hline Number of MCS & $4.7 \pm 3.2$ & 1 & 14 & 24 & 1 \\
\hline Pulse Repetition Time (s) & $0.0096 \pm 0.0012$ & 0.0078 & 0.0118 & 24 & 48 \\
\hline Phr1 duration (s) & $0.29 \pm 0.09$ & 0.12 & 0.47 & 24 & 2 \\
\hline Phr2 duration (s) & $0.28 \pm 0.15$ & 0.12 & 0.61 & 24 & 2 \\
\hline Phr3 duration (s) & $5.35 \pm 4.87$ & 0.63 & 16.74 & 24 & 2 \\
\hline Df $(\mathrm{Hz})$ first pulses & $485.6 \pm 243.6$ & 31.3 & 1000 & 22 & 24 \\
\hline $\mathrm{Df}(\mathrm{Hz})$ last pulses & $548.5 \pm 257.6$ & 187.5 & 1125 & 22 & 24 \\
\hline
\end{tabular}

n: number of analysed individuals, N: number of analysed signals per individual, MCS: Male Calling Song, Phr1: phrase 1, Phr2: phrase 2, Phr3: phrase 3. Df: dominant frequency of either the first or the last pulses within the phrases

with the highest and lowest number of recorded signals from a male being 14 and 1, respectively. The Male Calling Signal (MCS) consisted of a series of pulse trains (defined as 'phrases') composed of a rapid succession of broad-band pulses (Table 1, Fig. 1A, 1B, 1C and 1D). The male phrases were grouped in function of their spectral and temporal parameters, which clearly changed as the MCS proceeded. In particular, the first emitted phrase ('phrases 1') was followed by a series of pulse trains ('phrases 2') (Fig. 1B), whose first and last pulses had a lower relative amplitude compared to the first (Friedman Statistic; $X^{2}=6.5$, df $=1$, $p=0.02$ ) and last pulses (Friedman Statistic; $X^{2}=18.2$, df $=1, p<0.001)$ of the phrase 1 . The final pulses significantly differed between phrases 1 and 2 also in the PRT (Friedman Statistic; $\left.X^{2}=3.9, \mathrm{df}=1, p=0.04\right)$, while the PRT of the first pulses did not differ between phrases (Friedman Statistic; $X^{2}$ $=2.2, \mathrm{df}=1, p=0.1)$. Phrase 1 was emitted once, while the number of phrases 2 within a signal varied among individuals $(30 \pm 9 ; n=22 ; \mathrm{N}=2)$, nevertheless the durations of phrases 1 and 2 were similar (Friedman Statistic; $X^{2}=64.9$, $\mathrm{df}=3, p=1)$. After the sequence of phrase 2, the MCS finished with a series of longer (Friedman Statistic; $X^{2}=64.9$, $\mathrm{df}=3, p<0.001$ ) pulse trains (named 'phrase 3') (Fig. 1C). The first pulses of phrase 3 had higher relative amplitude when compared to the first pulses of phrase 2 (Friedman Statistic; $X^{2}=18.2$, df $\left.=1, p<0.001\right)$. Similarly, the relative amplitude of the final pulses of phrase 3 was higher than the amplitude of the last pulses of phrase 2 (Friedman Statistic; $X^{2}=14.7, \mathrm{df}=1, p<0.001$ ). In addition, the final pulses of phrase 3 had significantly higher PRT (Friedman Statistic; $X^{2}=8$, df $\left.=1, p<0.001\right)$ than the final pulses of phrase 2 . The duration of phrase 3 was highly variable, ranging from a minimum of $0.62 \mathrm{~s}$ to a maximum of $16.7 \mathrm{~s}$ (5.34 $\pm 4.86 \mathrm{~s}, \mathrm{n}=22 ; \mathrm{N}=2)$. Phrases 1 and 3 differed in their duration (Friedman Statistic; $X^{2}=64.9$, df $=3, p<0.001$ ) and in the PRT of the final pulses (Friedman Statistic; $X^{2}$ $=28.5, \mathrm{df}=3, p<0.001)$. Moreover, the internal structure differed within each phrase, since both the duration and the PRT were significantly different between the first and last pulses (Table 2).

\subsubsection{Females}

None of the females tested individually $(n=37)$ emitted spontaneous calls in the given time.

\subsubsection{Pairs}

Pair formation in $B$. cockerelli could be divided in three phases: (i) identification, (ii) localisation, and (iii) copulation. Vibrational signals were emitted during the first two phases, while during copulation both male and female were silent. Identification started with the emission of a MCS (male signalling rate $=51.6 \%, \mathrm{n}=62$ ) that could elicit the onset of a vibrational duet $(\mathrm{n}=25$, Table 3 , Fig. $2 \mathrm{~A}$ and $2 \mathrm{~B})$ with a receptive female (female response rate $=78 \%$ ) that emitted the Female Response Signal (FRS; Table 4, Fig. 2A). The FRS consisted of a long series of pulse trains (or 'phrases'), with the number ranging from 2 to 37 (Table 4) and whose duration was very variable (Table 4). The female phrases were not grouped since there were neither a clear temporal nor spectral pattern throughout their emission, as observed in the MCS. Nonetheless, there were significant differences in the spectral and temporal features within the female phrases, in particular in terms of dominant frequency (Friedman Statistic; $X^{2}=6.76=, \mathrm{df}=1, p<0.001$ ), amplitude (Friedman Statistic; $X^{2}=6.76$, df $=1, p<0.001$ ), duration (Friedman Statistic; $X^{2}=21.16$, $\mathrm{df}=1, p<0.001$ ), and PRT (Friedman Statistic; $X^{2}=\mathrm{df}=1, p<0.001$ ) between the first and final pulses of each pulse trains. Spectral and temporal parameters were significantly different between the MCS and the FRS; in particular, they differed both in the duration of both the first (Friedman Statistic; $X^{2}=14.73, \mathrm{df}=1, p<0.001$ ) and the last (Friedman Statistic; $X^{2}=21.73$, df $=1, p<0.001$ ) pulses within the phrases and in the frequency composition of the first (Friedman Statistic; $X^{2}=6.4016, \mathrm{df}=1, p<0.001$ ) 


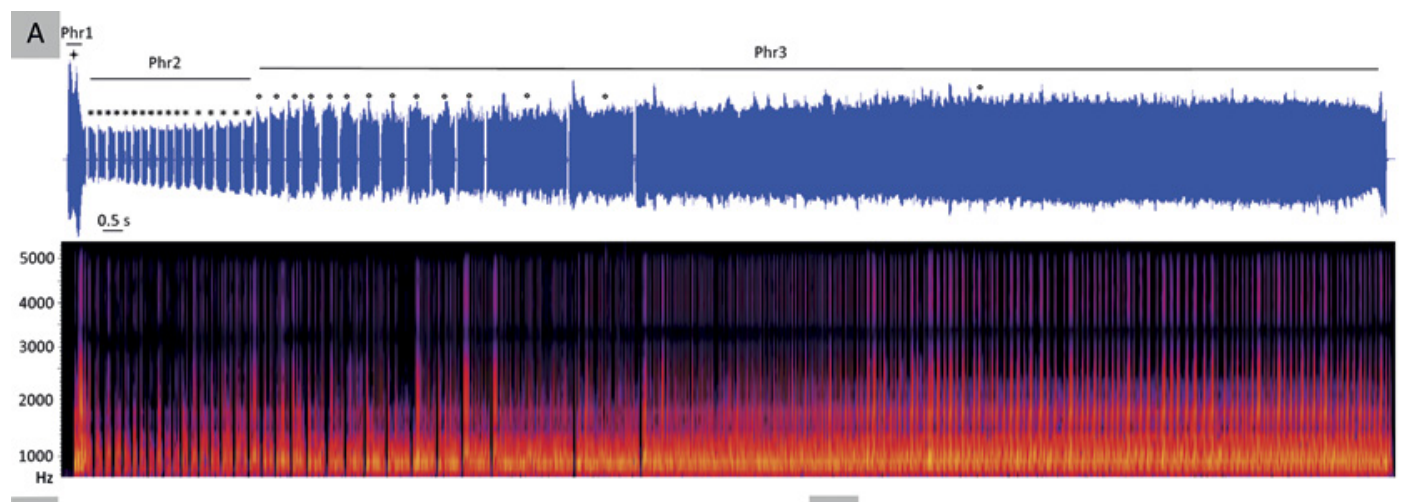

B

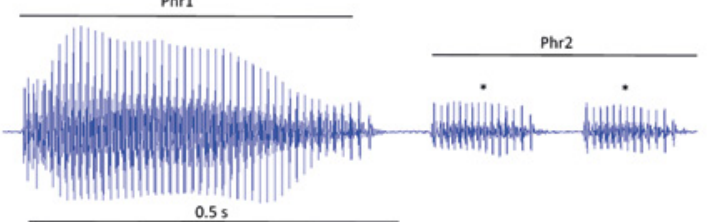

C
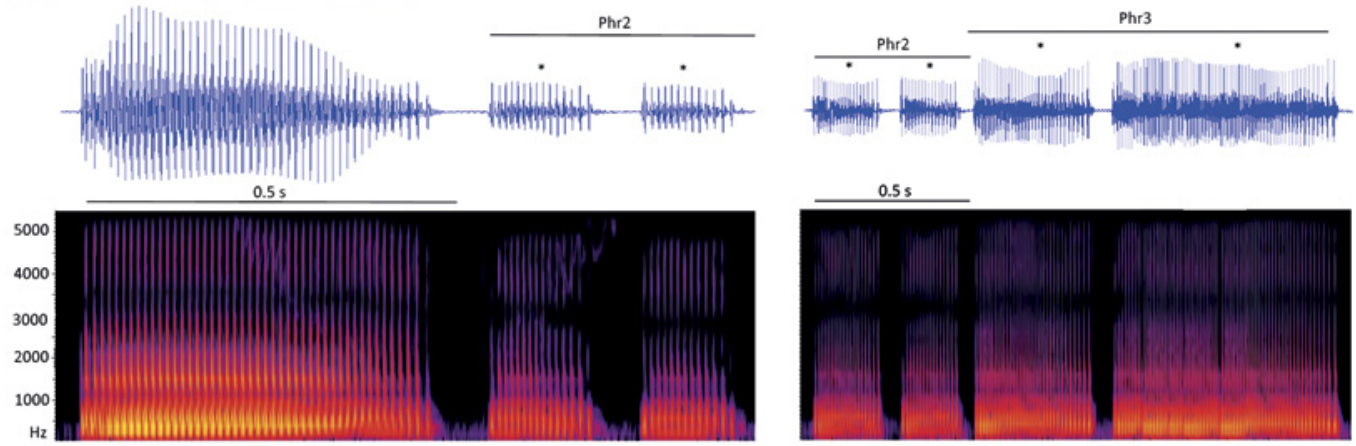

D
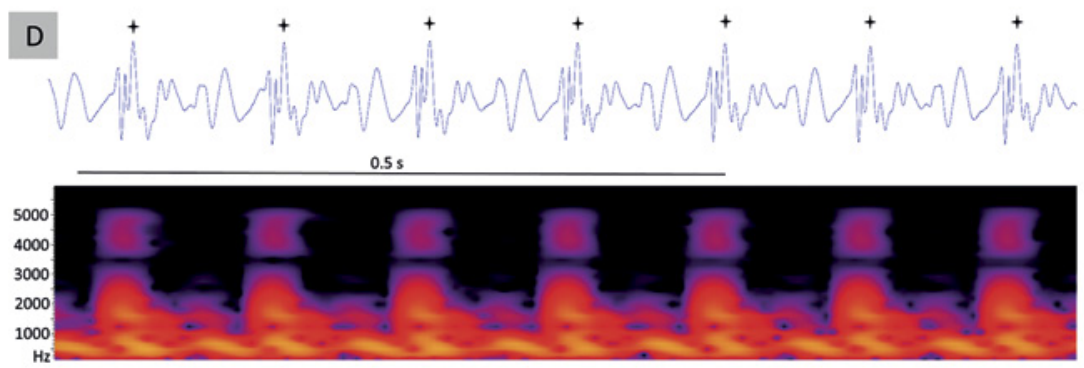

Fig. 1. Oscillogram (above) and spectrogram (below) of the Male Calling Signal (MCS) of Bactericera cockerelli. A. Entire MCS. B. Detail of the first section of a MCS. C. Detail of the last section of a MCS. D. Detail of the pulses emitted within a phrase of a MCS. Phr1: phrase 1, Phr2: series of phrase 2, Phr3: series of phrase 3. Asterisks indicate each phrase emitted within the MCS, diamonds indicate each pulse emitted within a phrase.

and the last (Friedman Statistic; $X^{2}=2.80, \mathrm{df}=1, p=0.02$ ) pulses within the phrases. The durations of MCS and FRS were significantly different from each other (Wilcoxon's test; $\mathrm{z}=4.6, p<0.001)$. The female response always overlapped the final part of the MCS and continued after its end, while further MCSs were emitted when the female ceased to reply. The male searching behaviour occurred during the long female response (localisation phase). Mating was achieved if the male was capable to maintain the duet until he reached the female, which remained stationary on the leaf (mating success of duetting males $=76 \%, \mathrm{n}=25$ ). Interestingly, $12.5 \%$ of the duets $(n=25)$ were started by the female with emission of a Female Attraction Signal (FAS), which consisted of a series of pulse trains (Table 5, Fig. 3A and 3B). The FAS could elicit the emission of the MCS, and thus the onset of a duet and the male search. In one case, the male started to search after the emission of the FAS, and silently reached the signalling female and mated with her. Similarly, 9.7\% of the tested males $(n=62)$ reached the female without emitting any vibrational signal, while $38.7 \%$ of males established and maintained a duet until successfully localisation of the mate. Two females (out of 25) ceased to reply after having established a duet even when the male continued to emit MCSs, while three males (out of 25) did not find the female in the given time of the trial.

Audio files of the MCS, FAS and duet are provided as supplementary material in Online Resources 1, 2, and 3, respectively. A flow chart summarising the pair formation process in $B$. cockerelli is provided as supplementary material (Fig. S1). 
Table 2. Differences in the temporal parameters between the beginning and the end of each phrase of the Male Calling Signal. Friedman test (nonparametric repeated measures ANOVA) with replications followed by pairwise multiple comparisons.

\begin{tabular}{|c|c|c|c|c|c|}
\hline Phrase & Parameter & Chi-Square & $p$ & $\mathrm{n}$ & $\mathbf{N}$ \\
\hline Phr1 & Duration (s) & 17.9 & $<0.001$ & 22 & 12 \\
\hline Phr2 & Duration (s) & 21.7 & $<0.001$ & 22 & 12 \\
\hline $\mathrm{Phr} 3$ & Duration (s) & 17.7 & $<0.001$ & 22 & 12 \\
\hline Phr1 & Pulse Repetition Time (s) & 72.9 & $<0.001$ & 22 & 12 \\
\hline $\mathrm{Phr} 2$ & Pulse Repetition Time (s) & 104.8 & $<0.001$ & 22 & 12 \\
\hline Phr3 & Pulse Repetition Time (s) & 120.1 & $<0.001$ & 22 & 12 \\
\hline
\end{tabular}

n: number of analysed individuals, N: number of analysed signals per individual, MCS: Male Calling Signal, Phr1: phrase 1, Phr2: phrase 2, Phr3: phrase 3. Significance $(\mathrm{p}<0,05)$ shown in bold

Table 3. Features of the male-female duet in Bactericera cockerelli.

\begin{tabular}{|c|c|c|c|c|c|}
\hline & Mean \pm SD & Min & Max & n & $\mathbf{N}$ \\
\hline Latency from first duet (s) & $392.7 \pm 272.7$ & 30.07 & 823.9 & 25 & 1 \\
\hline Female Reply Latency (s) & $12.3 \pm 7.1$ & 5.2 & 41.8 & 25 & 1 \\
\hline Searching time (s) & $404.5 \pm 436.5$ & 62.1 & 1461.6 & 20 & 1 \\
\hline Female Replying Rate & $0.9 \pm 0.1$ & 0.6 & 1 & 25 & 1 \\
\hline
\end{tabular}

Female Reply Latency: delay of the female signal from the onset of the Male Calling Signal, searching time: time between the onset of the male search and the copulation, Female Replying Rate: rate between the total number of female replies and male signals during the trial, $\mathrm{n}$ : number of analysed individuals, $\mathrm{N}$ : number of analysed signals per individual

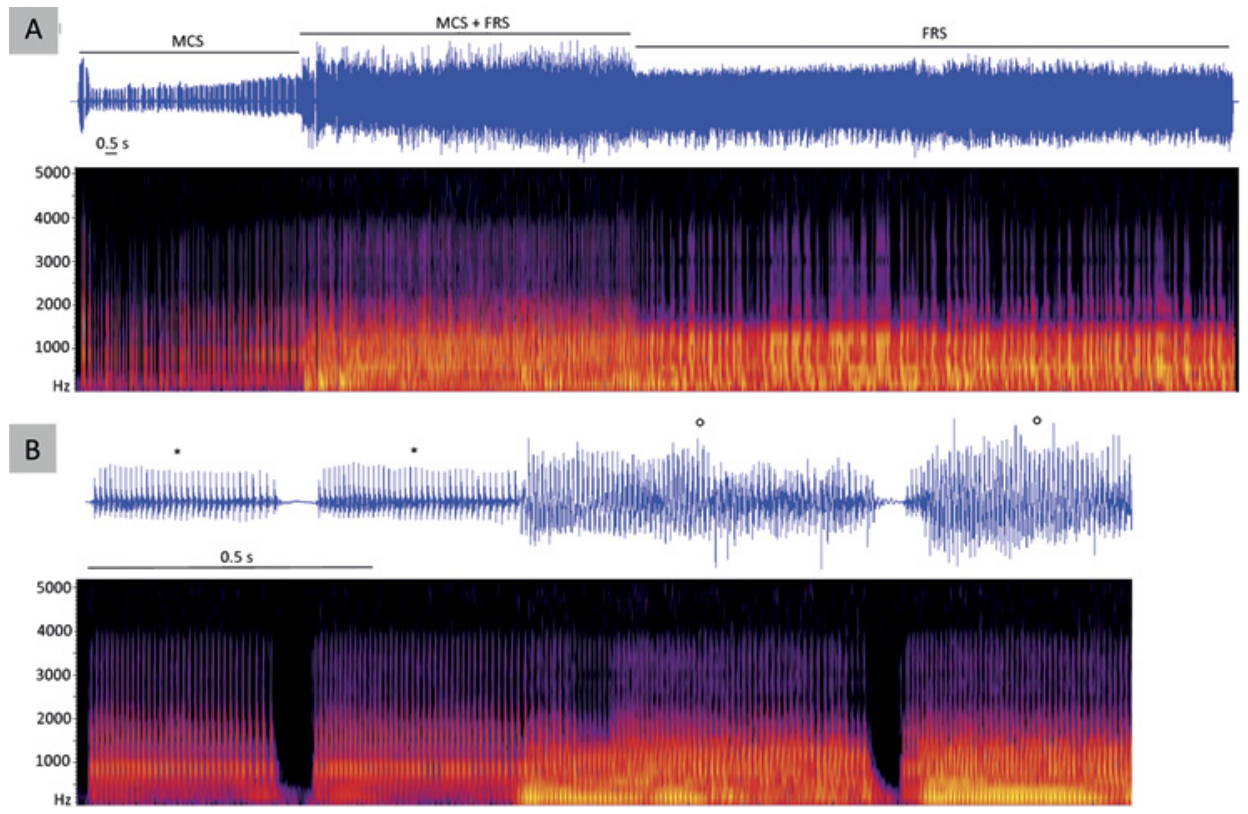

Fig. 2. Oscillogram (above) and spectrogram (below) of the male-female duet in Bactericera cockerelli. A. Entire duet, consisting of a MCS and a FRS. B. Detail of a duet, showing the overlap between the MCS and the FRS. Asterisks indicate the pulse trains within the MCS, empty circles indicate the overlap between the male and female pulse trains. MCS: Male Calling Signal, FRS: Female Response Signal. 
Table 4. Features of the Female Response Signal (FRS) of Bactericera cockerelli.

\begin{tabular}{|c|c|c|c|c|c|}
\hline & Mean \pm SD & Min & Max & $\mathbf{n}$ & $\mathbf{N}$ \\
\hline Duration of FRS (s) & $42.8 \pm 19.4$ & 10.5 & 100.6 & 25 & 2 \\
\hline Number of FRS & $15.3 \pm 9.9$ & 2 & 41 & 25 & 1 \\
\hline Phrases duration (s) & $5.64 \pm 5.04$ & 0.60 & 24.04 & 25 & 2 \\
\hline Df (Hz) first pulses & $694.1 \pm 293.8$ & 303.8 & 1488.8 & 25 & 50 \\
\hline $\mathrm{Df}(\mathrm{Hz})$ last pulses & $749.3 \pm 299.3$ & 240 & 1458.8 & 25 & 50 \\
\hline
\end{tabular}

n: number of analysed individuals, N: number of analysed signals per individual, Df: dominant frequency of either the first or the last pulses within the phrases

Table 5. Temporal and spectral parameters of the Female Attraction Signal (FAS) of B. cockerelli.

\begin{tabular}{lccccc}
\hline & Mean \pm SD & Min & Max & n & N \\
\hline Duration of FAS (s) & $29.2 \pm 3.8$ & 24.3 & 33.4 & 38 & 4 \\
Number of phrases & $29 \pm 14.7$ & 7 & 1.48 & 4 & 1 \\
Phrases duration (s) & $0.66 \pm 0.56$ & 0.31 & 667.5 & 4 & 50 \\
Df (Hz) first pulses & $336.6 \pm 225.7$ & 183.8 & 746.3 & 4 & 50 \\
Df (Hz) last pulses & $443.4 \pm 248.6$ & 187.5 & & 4 \\
\hline
\end{tabular}

$\mathrm{n}$ : number of analysed individuals, N: number of analysed signals per individual, Df: dominant frequency of either the first or the last pulses within the phrases

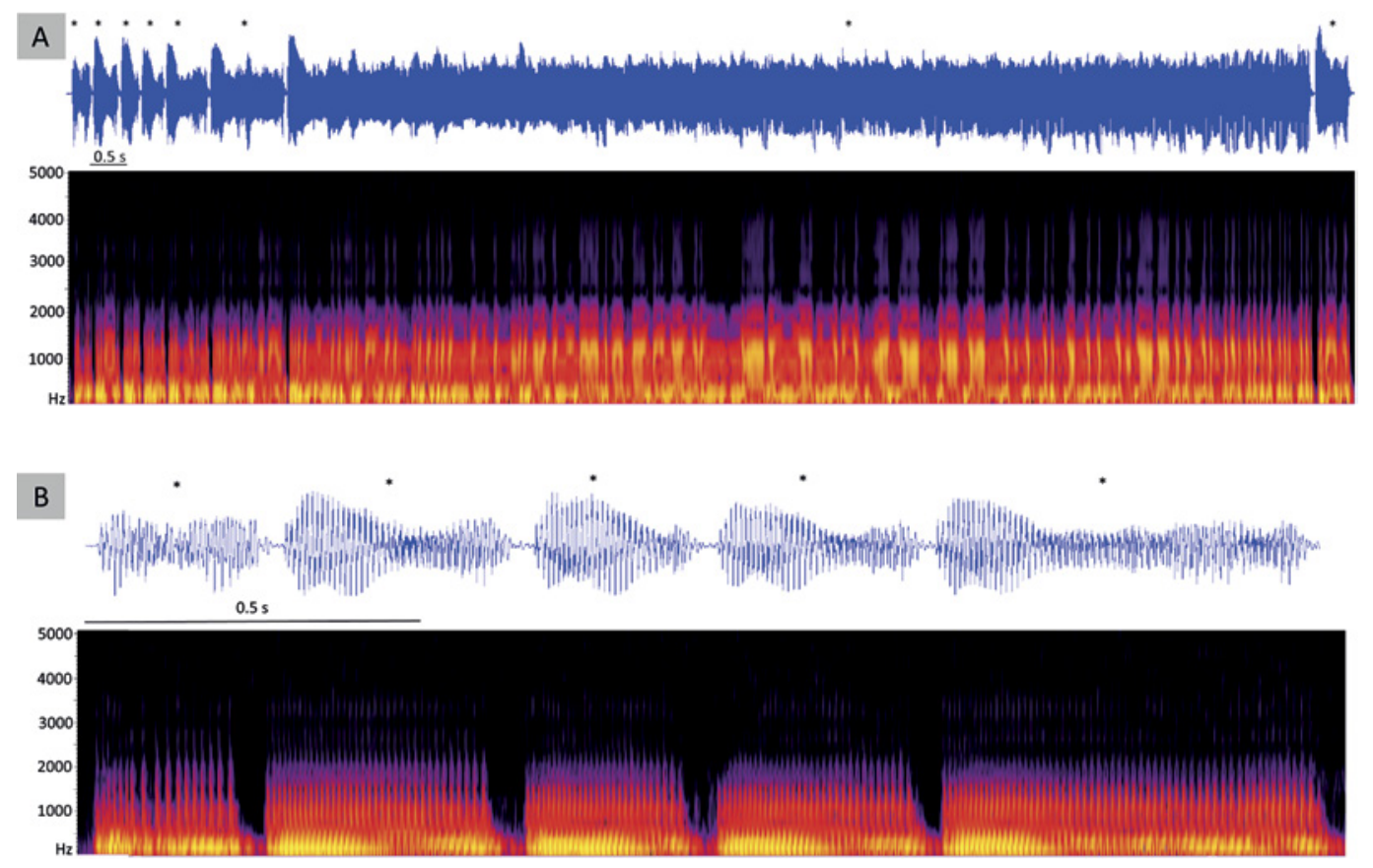

Fig. 3. Oscillogram (above) and spectrogram (below) of a Female Attraction Signal (FAS) of Bactericera cockerelli. A. Entire FAS. B. Detail of the first section of a FAS. Asterisks indicate each phrase emitted within the signal. 


\subsection{Test 2: Signal playback trials}

In Test 2a (Table 6), the number of males that emitted at least one MCS (1) and touched the mini shaker (4) did not differ between treatment with the playback and silent control. In contrast, the number of males that reached the signal source (stimulation point, (3)) and spent at least 1 minute nearby (6) during playback was significantly higher in the treatment with the playback than in the silent control. In Test $2 b$ (Table 7), the number of signalling males (1) and the number of individuals that reached the stimulation point (3), touched the mini shaker (4) and spent time on the stimulation point (6) when the mini shaker was on was significantly higher in the group treated with the playback than in the silent control group. When comparing insect responses to the playbacks used in Test $2 a$ and $2 b$, there were no significant difference in parameters (1), (2), (3), (4), (5), and (6) between the playback treatments (Table 8). The searching time (5) also did not differ between the playback treatments (Kruskal-Wallis Statistic, $\left.X^{2}=1.48, \mathrm{df}=1, p>0.05\right)$. However, the number of duetting males (7) was significantly higher when males were treated with the FPB2 (Test $2 b$ ) than when they were treated with the FPB1 (Test 2a) (Table 8).

\section{Discussion}

In this study, we described the mating behaviour and the associated vibrational signals of the tomato potato psyllid, B. cockerelli. We provide evidence that the sexual behaviour of males is vulnerable to manipulation, thus the development of a future vibrational pest control tool is worthy of further exploration. B. cockerelli shares several similarities with other psyllid species in terms of mating behaviour and emission of vibrational signals. For instance, the movement of the wings in a vertical plane during signalling suggests that vibrations are produced by stridulation, as previously proposed for B. cockerelli (Sullivan et al., submitted for publication) and for many Psylloidea, where the forewing act as a 'plectrum' that rubs against structures on the thorax (the 'pars stridens') (Taylor 1985; Tishechkin 2005; Eben et al. 2015; Wood et al. 2016; Liao et al. 2019). Also, the pair formation process resembled the general scheme described for other psyllids in which a male and a female established a vibrational duet (Tishechkin 2005; Percy et al. 2006). Similar to these species, the $B$. cockerelli male was the first to emit a calling signal, while the female did not produce spontaneous signals in absence of a potential partner and only replied to the male. However, during copulation, neither the male nor the female produced vibrations, possibly because there was no need to maintain the female motivation and/or due to difficulties in using the wings to stridulate while mating.

As reported for many Australian Psylloidea species (Percy et al. 2006), B. cockerelli male and female signals were structured in phrases and differed in duration and dominant frequency of the pulses. Moreover, the female reply occurred before the end of the male signal, similar to some Schedotrioza spp. and Trioza spp. (Percy et al. 2006), and to other hemipteran insects such as Aphrodes makarovi (Cicadellidae) (De Groot et al. 2012). De Groot and colleagues (2012) suggested that the partial overlap between male and female signals could be advantageous for the female, if this could reduce the risk of localisation by eavesdropping predators, which could perceive the signal arriving from two different sources. As for A. makarovi (De Groot et al. 2012), the long and complex male call in B. cockerelli could also ensure species recognition, thus the female reply would occur when the male signal reaches a critical duration and before its end. In this regard, the female replying latency was quite variable, ranging from a minimum of 5.2 to a maximum of 41.8 seconds from the beginning of the MCS. The time between the onset of the male calling signal and the onset of the female reply could be used by the female to evaluate the quality of the potential partner. In this way, the female could assess the MCS before emitting her signal, and choose whether to reply and elicit the male search. In fact, some $B$. cockerelli females $(20 \%)$ did not respond to the male calling signal in our trials. Nonetheless, after the establishment of a duet, mating was successfully achieved by most males ( $90 \%$ of duetting pairs mated), suggesting that female choice likely occurred together with the identification, during the first phase of pair formation. Mating success of psyllids males is usually high (Eben et al. 2015; Liao \& Yang 2015; Liao et al. 2016), since females are ready to mate soon after eclosion as adults (Burts \& Fischer 1967) and promptly reply to male vibrations (Percy et al. 2006).

Nevertheless, psyllid mating behaviour could depend on additional signals (e.g., specific odours), which could elicit the female motivation and increase the ability of males to reach a mate. Psyllid species such as Diaphorina citri and $B$. cockerelli bear complex sensory arrays on the antennae, which permit chemical detection, most likely used to locate host plants and mates (Arras et al. 2012). Although vibrational signals seem to be the primary sensory modality in B. cockerelli for mate finding, few males $(10 \%, \mathrm{n}=62)$ successfully mated with the female without the emission of any signal. The small size of our experimental substrate (the leaf) could have been advantageous for the male and thus he could have reached the female by chance. Nevertheless, we cannot exclude the possible role of chemical or visual stimuli, which could be used by the male to perceive the presence of a female. Accordingly, these stimuli could allow the male to delay or even prevent the emission of a calling signal, if he can use them either to orient closer to or reach the female. In this way, the male could decrease both the mating success of eavesdropping rivals and probability of being attacked by a predator (Wenninger et al. 2009).

The role of semiochemicals in psyllids has been reported for several species (Soroker et al. 2004; Horton \& Landolt 2007; Horton et al. 2008; Wenninger et al. 2009) including B. cockerelli (Guédot et al. 2010). In this regard, B. cockerelli 
Table 6. Results of the $G$ test ( $G$ and $p$ are given) in a contingency table (2x2) of Test 1 for treatment (playback stimulation, FPB1+) and control (FPB1-) trials.

\begin{tabular}{|c|c|c|c|c|}
\hline & FPB1+ & FPB1- & G & $p$ \\
\hline $\mathrm{n}$ & 19 & 19 & & \\
\hline (1) signalling males & 10 & 8 & 0.4 & $\mathrm{NS}(>0.05)$ \\
\hline (3) males that reached stimulation point & 6 & 1 & 4.8 & $<0.001$ \\
\hline (4) males that touched mini shaker & 3 & 1 & 1.2 & NS $(>0.05)$ \\
\hline (6) close to stimulation point for more than $1 \mathrm{~min}$ & 6 & 0 & 5 & $<\mathbf{0 . 0 0 1}$ \\
\hline
\end{tabular}

n: number of tested males. Significance shown in bold

Table 7. Results of $G$ test $(G$ and $p)$ in a contingency table $(2 \times 2)$ of Test 2 for treatment (playback stimulation, FPB2+) and control (FPB2-) trials.

\begin{tabular}{|c|c|c|c|c|}
\hline & FPB2+ & FPB2- & $\mathbf{G}$ & $p$ \\
\hline $\mathrm{n}$ & 19 & 19 & & \\
\hline (1) signalling males & 15 & 15 & 11.1 & $<0.001$ \\
\hline (3) males that reached stimulation point & 10 & 2 & 8.3 & $<0.001$ \\
\hline (4) males that touched mini shaker & 6 & 0 & 5 & $<0.05$ \\
\hline (6) close to stimulation point for more than $1 \mathrm{~min}$ & 10 & 0 & 11 & $<0.001$ \\
\hline
\end{tabular}

$\mathrm{n}$ : number of tested males. Significance shown in bold

Table 8. Results of $G$ test ( $G$ and $p)$ in a contingency table $(2 \times 2)$ between treatment 1 (playback1, FPB1+) and treatment 2 (playback 2, FPB2+).

\begin{tabular}{|c|c|c|c|c|}
\hline & FPB1+ & FPB2+ & $\mathbf{G}$ & $p$ \\
\hline $\mathrm{n}$ & 19 & 19 & & \\
\hline (2) searching males & 9 & 11 & 0.4 & $\mathrm{NS}(>0.05)$ \\
\hline (3) males that reached stimulation point & 6 & 10 & 1.7 & $\mathrm{NS}(>0.05)$ \\
\hline (4) males that touched mini shaker & 3 & 6 & 1.3 & $\mathrm{NS}(>0.05)$ \\
\hline (6) close to SP for more than $1 \mathrm{~min}$ & 6 & 10 & 1 & $\mathrm{NS}(>0.05)$ \\
\hline (7) duetting males & 8 & 15 & 5.6 & $<0.05$ \\
\hline
\end{tabular}

$\mathrm{n}$ : number of tested males

males were weakly attracted to conspecifics' odorants and, in a two-choice test, they moved preferentially towards live males or females, rather than towards the respective insect extracts alone. Females, on the other hand, were not attracted by conspecifics' odorants, while in the two-choice test they showed neither preference nor avoidance (Guédot et al. 2010). However, this study did not take into account the potential role of vibrational signals that could have potentially elicited males' search in the two-choice tests, while females did not move since mate searching is accomplished by males. At any rate, it would be worthy of investigation to assess whether the combination of chemical and vibrational signals would increase the male searching activity and finally confirm the use of multiple signals for mate finding in psyllids.

In this regard, experiments involving multiple signals could provide both new ethological insights about psyllids and be useful for development of integrated pest management techniques. Although female sex pheromones are involved in the mating behaviour of two species of Cacopsylla (Soroker et al. 2004; Horton \& Landolt 2007), and Cacopsylla pyri uses vibrations to identify and localise potential partners (Eben et al. 2015), synergy between chemical and vibrational signals has not been yet well explored. Additional evidence of the role of chemical signals in psyllids' mating behaviour could be from the signalling activity of $B$. cockerelli female. In contrast with most Psylloidea, mating was achieved when the female emitted the first vibrational signal $(16 \%, n=62)$, eliciting the male signalling and searching activity. Since none of the females spontaneously produced a signal when individually tested, female signalling could depend on the perception of the male odour.

Alternatively, other signals could indicate the presence of a conspecific; for instance, the female could have perceived 
the incidental vibrations produced by the male while walking or feeding on the leaf. In fact, the signalling rate of $D$. citri males was not affected by the presence of female odours (Wenninger et al. 2009), while the playback of specific vibrational signals to the plant evoked calling signals from $D$. citri males that eventually located the source of the signals (Rohde et al. 2013), suggesting that the latter could be considered as a lure. Therefore, not only the mating behaviour of this species strongly relies on vibrations, but it is vulnerable to manipulation as well.

Similarly, our female playbacks elicited the signalling activity of $B$. cockerelli males that eventually reached and remained in vicinity of the stimulation point. The number of males that established a proper duet was higher when we transmitted the female playback 2 , whose second signal was as long as the natural female response, while the second signal of the female playback 1 was shorter. Since species identification usually relies on the estimation of the temporal parameters of the mating signals (Claridge 1985; Čokl \& Virant-Doberlet 2003; Virant-Doberlet et al. 2014), males likely preferred the playback that most resembled a conspecific female response. In addition, a synthetic stimulus able to efficiently attract a male should necessarily occur in a specific time window to be reliable. The trapping system used for $D$. citri, for example, was improved using a device that automatically emitted the female playback after the detection of a male calling signal (Mankin et al. 2013). However, once recognition occurred, the number of $B$. cockerelli males that reached the stimulation point did not significantly differ between the group treated with the FPB1 (Test 2a) and the group treated with the FPB2 (Test 2b). Although the longer playback elicited higher male signalling activity (in terms of duetting), likely it was not more informative than the female playback 1 about direction and distance from the source.

Besides species identification, the temporal features of a signal can convey relevant directional orientation. In $A$. makarovi, the success of the male in locating the female was significantly affected by the length of the female response signal (Kuhelj et al. 2015), while in the planthopper Hyalesthes obsoletus, the spectral features of the female call influenced the signalling and searching activity of the male, which moved towards the preferred female playback in a series of two choice tests (Mazzoni et al. 2015). Therefore, to develop an efficient behavioural manipulation strategy for B. cockerelli, research should focus on the temporal and spectral parameters of the female playback, specifically determining which characteristics provide directional cues to the male and maintain his motivation to search.

To conclude, we have provided evidence that vibrational signals are crucial for mate finding in B. cockerelli and that the development of a future vibrational control tool against this pest may be technically feasible. Indeed, we suggest further research aimed to set more attractive stimuli by improving the tested playback signals and/or implementing them with a chemical cue.
Author contribution statement: SA, TES, DMS conceived and designed the research. SA and TES conducted the experiments. SA analysed the data. SA and VM wrote the manuscript. All authors read and approved the manuscript.

Acknowledgements: The Ministry of Business Innovation and Employment contract "Realising Potato Export Growth: C11X1308" enabled the senior author to conduct this work in New Zealand as part of her $\mathrm{PhD}$ at the University of Trento.

We are very grateful to Professor Phil Taylor of Macquarie University for extended loans of the laser vibrometer.

\section{Compliance with ethical standards}

Conflict of interest: There are no conflicts of interest involving the authors.

Animal rights statement: All applicable international, national, and/or institutional guidelines for the care and use of animals were followed.

Human rights statement: This article does not contain any studies with human participants performed by any of the authors.

\section{References}

Alexander, R. D. (1967). Acoustical Communication in Arthropods. Annual Review of Entomology, 12(1), 495-526. https://doi. org/10.1146/annurev.en.12.010167.002431

Arras, J., Hunter, W., \& Bextine, B. (2012). Comparative Analysis of Antennae Sensory Arrays in Asian Citrus Psyllid, Diaphorina citri, and Potato Psyllid, Bactericera cockerelli (Hemiptera). Southwestern Entomologist 37(1), 1-12.

Berry, N. A., Walker, M. K., \& Butler, R. C. (2009). Laboratory studies to determine the efficacy of selected insecticides on tomato/potato psyllid. New Zealand Plant Protection, 62, 145151. https://doi.org/10.30843/nzpp.2009.62.4784

Booij, C. J. H. (1982). Biosystematics of the Muellerianella complex (Homoptera, Delphacidae), interspecific and geographic variation in acoustic behaviour. Zeitschrift für Tierpsychologie, 58(1), 31-52. https://doi.org/10.1111/j.1439-0310.1982.tb00307.x

Broughton, W. B. (1963). Method in bio-acoustic terminology. In R. G. Busnel (Ed.), Acoustic Behavior of Animals. New York: Elsevier Publishing Co.

Burts, E. C., \& Fischer, W. R. (1967). Mating behavior egg production and egg fertility in Pear psylla. Journal of Economic Entomology, 60(5), 1297-1300. https://doi.org/10.1093/jee/60. 5.1297

Claridge, M. F. (1985). Acoustic-signals in the Homoptera - behavior, taxonomy, and evolution. Annual Review of Entomology, 30(1), 297-317. https://doi.org/10.1146/annurev.en.30.010185. 001501

Cocroft, R. B., \& Rodríguez, R. L. (2005). The behavioral ecology of insect vibrational communication. Bioscience, 55(4), 323334. https://doi.org/10.1641/0006-3568(2005)055[0323:TBEOI $\mathrm{V}] 2.0 . \mathrm{CO} ; 2$

Čokl, A., \& Virant-Doberlet, M. (2003). Communication with Substrate-Borne Signals in Small Plant-Dwelling Insects. Annual Review of Entomology, 48(1), 29-50. https://doi. org/10.1146/annurev.ento.48.091801.112605 
De Groot, M., Derlink, M., Pavlovčič, P., Prešern, J., Čokl, A., \& Virant-Doberlet, M. (2012). Duetting behaviour in the leafhopper Aphrodes makarovi (Hemiptera: Cicadellidae). Journal of Insect Behavior, 25(5), 419-440. https://doi.org/10.1007/ s10905-011-9304-6

Derlink, M., Abt, I., Mabon, R., Julian, C., Virant-Doberlet, M., \& Jacquot, E. (2018). Mating behavior of Psammotettix alienus (Hemiptera: Cicadellidae). Insect Science, 25(1), 148-160. https://doi.org/10.1111/1744-7917.12379

Eben, A., Mühlethaler, R., Gross, J., \& Hoch, H. (2015). First evidence of acoustic communication in the pear psyllid Cacopsylla pyri L. (Hemiptera: Psyllidae). Journal of Pest Science, 88, 87-95. https://doi.org/10.1007/s10340-014-0588-0

Endler, J. A. (1992). Signals, signal conditions, and the direction of evolution. American Naturalist, 139, S125-S153. https://doi. org/10.1086/285308

Eriksson, A., Anfora, G., Lucchi, A., Lanzo, F., Virant-Doberlet, M., \& Mazzoni, V. (2012). Exploitation of Insect Vibrational Signals Reveals a New Method of Pest Management. PLoS One, 7(3), e32954. https://doi.org/10.1371/journal.pone.0032954

Foster, S. P., \& Harris, M. O. (1997). Behavioral manipulation methods for insect pest-management. Annual Review of Entomology, 42(1), 123-146. https://doi.org/10.1146/annurev. ento.42.1.123

Goolsby, J., Adamczyk, J., Bextine, B., Lin, D., Munyaneza, J., Bester, G., \& Lay, F. (2007). Development of an IPM Program for Management of the Potato Psyllid to Reduce Incidence of Zebra Chip Disorder in Potatoes. Yaredai Zhiwu Kexue, 59, 85-94.

Gordon, S. D., Sandoval, N., Mazzoni, V., \& Krugner, R. (2017). Mating interference of glassy-winged sharpshooters, Homalodisca vitripennis. Entomologia Experimentalis et Applicata, 164(1), 27-34. https://doi.org/10.1111/eea.12594

Guédot, C., Horton, D. R., \& Landolt, P. J. (2010). Sex Attraction in Bactericera cockerelli (Hemiptera: Triozidae). Environmental Entomology, 39(4), 1302-1308. https://doi.org/10.1603/ EN10048

Hall, D. G., Richardson, M. L., Ammar, E. D., \& Halbert, S. E. (2013). Asian citrus psyllid, Diaphorina citri, vector of citrus huanglongbing disease. Entomologia Experimentalis et Applicata, 146(2), 207-223. https://doi.org/10.1111/eea.12025

Hansen, A. K., Trumble, J. T., Stouthamer, R., \& Paine, T. D. (2008). A new huanglongbing species, "Candidatus liberibacter psyllaurous," found to infect tomato and potato, is vectored by the psyllid Bactericera cockerelli (Sulc). Applied and Environmental Microbiology, 74(18), 5862-5865. https://doi. org/10.1128/AEM.01268-08

Horton, D. R., \& Landolt, P. J. (2007). Attraction of male pear psylla, Cacopsylla pyricola, to female-infested pear shoots. Entomologia Experimentalis et Applicata, 123(2), 177-183. https://doi.org/10.1111/j.1570-7458.2007.00537.x

Horton, D. R., Guedot, C., \& Landolt, P. J. (2008). Attraction of male summerform pear psylla to volatiles from female pear psylla: Effects of female age, mating status, and presence of host plant. Canadian Entomologist, 140(2), 184-191. https://doi. org/10.4039/n08-001

Kanmiya, K. (2006). Mating Behaviour and Vibratory Signals in Whiteflies (Hemiptera: Aleyrodidae). In S. Drosopoulos \& M. F. Claridge (Eds.), Insect Sounds and Communication, Physiology, Behaviour, Ecology, and Evolution (pp. 365-379). CRC Press Boca Raton.
Krugner, R., \& Gordon, S. D. (2018). Mating disruption of Homalodisca vitripennis (Germar) (Hemiptera: Cicadellidae) by playback of vibrational signals in vineyard trellis. Pest Management Science, 74(9), 2013-2019. https://doi.org/ $10.1002 /$ ps.4930

Kuhelj, A., De Groot, M., Blejec, A., \& Virant-Doberlet, M. (2015). The effect of timing of female vibrational reply on male signalling and searching behaviour in the leafhopper Aphrodes makarovi. PLoS One, 10(10), e0139020. https://doi.org/10.1371/ journal.pone.0139020

Liao, Y. C., \& Yang, M. M. (2015). Acoustic Communication of Three Closely Related Psyllid Species: A Case Study in Clarifying Allied Species Using Substrate-borne Signals (Hemiptera: Psyllidae: Cacopsylla). Annals of the Entomological Society of America, 108(5), 902-911. https://doi.org/10.1093/ aesa/sav071

Liao, Y. C., Huang, S. S., \& Yang, M. M. (2016). Substrate-Borne Signals, Specific Recognition, and Plant Effects on the Acoustics of Two Allied Species of Trioza, With the Description of a New Species (Psylloidea: Triozidae). Annals of the Entomological Society of America, 109(6), 906-917. https://doi.org/10.1093/ aesa/saw060

Liao, Y. C., Wu, Z. Z., \& Yang, M. M. (2019). Vibrational behavior of psyllids (Hemiptera: Psylloidea): Functional morphology and mechanisms. PLoS One, 14(9), e0215196. https://doi.org/ 10.1371/journal.pone.0215196

Liefting, L. W., Sutherland, P. W., Ward, L. I., Paice, K. L., Weir, B. S., \& Clover, G. R. G. (2009). A New 'Candidatus Liberibacter' Species Associated with Diseases of Solanaceous Crops. Plant Disease, 93(3), 208-214. https://doi.org/10.1094/PDIS-93-30208

Liu, D., \& Trumble, J. T. (2007). Comparative fitness of invasive and native populations of the potato psyllid (Bactericera cockerelli). Entomologia Experimentalis et Applicata, 123(1), 35-42. https://doi.org/10.1111/j.1570-7458.2007.00521.x

Mankin, R. W., Rohde, B. B., Mcneill, S. A., Paris, T. M., Zagvazdina, N. I., \& Greenfeder, S. (2013). Diaphorina citri (Hemiptera: Liviidae) responses to microcontroller-buzzer communication signals of potential use in vibration traps. The Florida Entomologist, 96(4), 1546-1555. https://doi.org/ 10.1653/024.096.0437

Mazzoni, V., Lucchi, A., Cokl, A., Presern, J., \& Virant-Doberlet, M. (2009). Disruption of the reproductive behaviour of Scaphoideus titanus by playback of vibrational signals. Entomologia Experimentalis et Applicata, 133(2), 174-185. https://doi.org/10.1111/j.1570-7458.2009.00911.x

Mazzoni, V., Polajnar, J., \& Virant-Doberlet, M. (2015). Secondary spectral components of substrate-borne vibrational signals affect male preference. Behavioural Processes, 115, 53-60. https:// doi.org/10.1016/j.beproc.2015.02.019

Mazzoni, V., Polajnar, J., Baldini, M., Rossi Stacconi, M. V., Anfora, G., Guidetti, R., \& Maistrello, L. (2017). Use of substrate-borne vibrational signals to attract the Brown Marmorated Stink Bug, Halyomorpha halys. Journal of Pest Science, 90(4), 1219-1229. https://doi.org/10.1007/s10340-017-0862-z

Munyaneza, J. E. (2010). Psyllids as vectors of emerging bacterial diseases of annual crops. Southwestern Entomologist, 35(3), 471-477. https://doi.org/10.3958/059.035.0335

Nieri, R., \& Mazzoni, V. (2018). The reproductive strategy and the vibrational duet of the leafhopper Empoasca vitis. Insect 
Science, 25(5), 869-882. https://doi.org/10.1111/17447917.12454

Nieri, R., Mazzoni, V., Gordon, S. D., \& Krugner, R. (2017). Mating behavior and vibrational mimicry in the glassy-winged sharpshooter, Homalodisca vitripennis. Journal of Pest Science, 90(3), 887-899. https://doi.org/10.1007/s10340-017-0840-5

Pedigo, L. P., \& Rice, M. E. (2014). Entomology and pest management. Waveland Press.

Percy, D. M., Taylor, G. S., \& Kennedy, M. (2006). Psyllid communication: Acoustic diversity, mate recognition and phylogenetic signal. Invertebrate Systematics, 20(4), 431-445. https:// doi.org/10.1071/IS05057

Pertot, I., Caffi, T., Rossi, V., Mugnai, L., Hoffmann, C., Grando, M. S., ... Anfora, G. (2017). A critical review of plant protection tools for reducing pesticide use on grapevine and new perspectives for the implementation of IPM in viticulture. Crop Protection (Guildford, Surrey), 97, 70-84. https://doi.org/ 10.1016/j.cropro.2016.11.025

Polajnar, J., Eriksson, A., Lucchi, A., Anfora, G., Virant-Doberlet, M., \& Mazzoni, V. (2015). Manipulating behaviour with substrate-borne vibrations - potential for insect pest control. Pest Management Science, 71(1), 15-23. https://doi.org/10.1002/ ps.3848

Polajnar, J., Eriksson, A., Virant-Doberlet, M., \& Mazzoni, V. (2016). Mating disruption of a grapevine pest using mechanical vibrations: From laboratory to the field. Journal of Pest Science, 89(4), 909-921. https://doi.org/10.1007/s10340-015-0726-3

Rohde, B., Paris, T. M., Heatherington, E. M., Hall, D. G., \& Mankin, R. W. (2013). Responses of Diaphorina citri (Hemiptera: Psyllidae) to Conspecific Vibrational Signals and Synthetic Mimics. Annals of the Entomological Society of America, 106(3), 392-399. https://doi.org/10.1603/AN12150

Siegel, S., \& Castellan, N. J., Jr. (1988). Nonparametric statistics for the behavioral sciences ( $2^{\text {nd }}$ ed.). New York, NY, England: Mcgraw-Hill Book Company.

Soroker, V., Talebaev, S., Harari, A. R., \& Wesley, S. D. (2004). The role of chemical cues in host and mate location in the pear psylla Cacopsylla bidens (Homoptera: Psyllidae). Journal of Insect Behavior, 17(5), 613-626. https://doi.org/10.1023/B:JOIR. $0000042544.35561 .1 \mathrm{c}$

Steel, R. G. D. (1959). A Multiple Comparison Rank Sum Test: Treatments versus Control. Biometrics, 15(4), 560-572. https:// doi.org/10.2307/2527654

Taylor, K. L. (1985). A Possible Stridulatory Organ in Some Psylloidea (Homoptera). Australian Journal of Entomology, 24(1), 77-80. https://doi.org/10.1111/j.1440-6055.1985. tb00190.x

Teulon, D. A. J., Workman, P. J., Thomas, K. L., \& Nielsen, M. C. (2009). Bactericera cockerelli: Incursion, dispersal and current distribution on vegetable crops in New Zealand. New Zealand Plant Protection, 62, 136-144. https://doi.org/10.30843/nzpp. 2009.62.4783

Tishechkin, D. Y. (2003). Vibrational communication in Cercopoidea and Fulgoroidea (Homoptera: Cicadina) with notes on classification of higher taxa. Russian Entomological Journal, 12(2), 127-181.

Tishechkin, D. Y. (2005). Vibratory Communication in Psylloidea (Homoptera). In S. Drosopoulos \& M. F. Claridge (Eds.), Insect Sounds and Communication: Physiology, Behaviour, Ecology and Evolution (pp. 357-363). Boca Raton, New York: Taylor and Francis Group. https://doi.org/10.1201/9781420039337

Virant-Doberlet, M., \& Cokl, A. (2004). Vibrational communication in insects. Neotropical Entomology, 33(2), 121-134. https:// doi.org/10.1590/S1519-566X2004000200001

Virant-Doberlet, M., Mazzoni, V., De Groot, M., Polajnar, J., Lucchi, A., Symondson, W. O. C., \& Čokl, A. (2014). Vibrational Communication Networks: Eavesdropping and Biotic Noise. In R. B. Cocroft, M. Gogala, P. S. Hill, \& A. Wessel (Eds.), Studying Vibrational Communication (pp. 93-123). Berlin, Heidelberg: Springer Berlin Heidelberg; https:/doi.org/ 10.1007/978-3-662-43607-3_7

Virant-Doberlet, M., \& Zezlina, I. (2007). Vibrational communication of Metcalfa pruinosa (Hemiptera: Fulgoroidea: Flatidae). Annals of the Entomological Society of America, 100(1), 73-82. https://doi.org/10.1603/0013-8746(2007)100[73:VCOMPH]2.0 .CO;2

Wenninger, E. J., Hall, D. G., \& Mankin, R. W. (2009). Vibrational Communication Between the Sexes in Diaphorina citri (Hemiptera: Psyllidae). Annals of the Entomological Society of America, 102(3),547-555.https://doi.org/10.1603/008.102.0327

Wood, R., Peters, R., Taylor, G., \& Steinbauer, M. (2016). Characteristics of the Signals of Male Anoeconeossa bundoorensis Taylor and Burckhardt (Hemiptera: Aphalaridae) Associated with Female Responsiveness. Journal of Insect Behavior, 29(1), 1-14. https://doi.org/10.1007/s10905-0159539-8

The pdf version (Adobe JavaScript must be enabled) of this paper includes an electronic supplement: Fig. S1, Audiosupplement

Manuscript received: 24 December 2019

Revisions requested: 5 April 2020

Modified version received: 20 April 2020

Accepted: 11 May 2020 